\title{
Protective Effect of Metformin Against Walker 256 Tumor Growth is Not Dependent on Metabolism Improvement
}

\author{
Claudinéia Conationi da Silva Franco $^{a}$ Rosiane Aparecida Miranda ${ }^{a}$ \\ Júlio Cezar de Oliveira ${ }^{a}$ Luiz Felipe Barella ${ }^{a}$ Aryane Rodrigues Agostinho ${ }^{a}$ \\ Kelly Valério $\underline{\text { Prates }}^{\mathrm{a}}$ Ananda Malta ${ }^{\mathrm{a}}$ Amanda Bianchi Trombini ${ }^{\mathrm{a}}{ }^{\text {Rosana } \text { Torrezan }^{\mathrm{a}}}$ \\ Clarice Gravena ${ }^{a}$ Laize P. Tófolo ${ }^{a} \quad J u l i a n e ~ R o c h a ~ d e ~ S a n t ' A n n a^{b}$ \\ Marialba Avezum Alves de Castro Prado ${ }^{b}$ Camila Oliveira de Souza \\ Helenir Medri de Souzac Evandro José Beraldid Paulo Cezar de Freitas Mathias ${ }^{a}$
}

aLaboratory of Secretion Cell Biology, Department of Biotecnology, Genetics and Cell Biology, State University of Maringá, Maringá/PR, Brazil; ' Laboratory of Mutagenesis \& Genetics, Department of Cell Biology and Genetics, State University of Maringá, Maringá/PR, Brazil; 'Department of Physiological Sciences, State University of Londrina, Londrina/PR, Brazil; dDepartment of Morphological Sciences, State University of Maringá, Maringá/PR, Brazil

\section{Key Words}

Metformin • Walker 256 tumor • Apoptosis • Metabolism

\begin{abstract}
Background/Aims: The objective of the current work was to test the effect of metformin on the tumor growth in rats with metabolic syndrome. Methods: We obtained pre-diabetic hyperinsulinemic rats by neonatal treatment with monosodium L-glutamate (MSG), which were chronically treated every day, from weaning to 100 day old, with dose of metformin (250 $\mathrm{mg} / \mathrm{kg}$ body weight). After the end of metformin treatment, the control and MSG rats, treated or untreated with metformin, were grafted with Walker 256 carcinoma cells. Tumor weight was evaluated 14 days after cancer cell inoculation. The blood insulin, glucose levels and glucoseinduced insulin secretion were evaluated. Results: Chronic metformin treatment improved the glycemic homeostasis in pre-diabetic MSG-rats, glucose intolerance, tissue insulin resistance, hyperinsulinemia and decreased the fat tissue accretion. Meanwhile, the metformin treatment did not interfere with the glucose insulinotropic effect on isolated pancreatic islets. Chronic treatment with metformin was able to decrease the Walker 256 tumor weight by $37 \%$ in control and MSG rats. The data demonstrated that the anticancer effect of metformin is not related to its role in correcting metabolism imbalances, such as hyperinsulinemia. However, in morphological assay to apoptosis, metformin treatment increased programmed cell death. Conclusion: Metformin may have a direct effect on cancer growth, and it may programs the rat organism to attenuate the growth of Walker 256 carcinoma.

C.C. da Silva Franco and R.A. Miranda contributed equally to this work.




\section{Introduction}

An epidemic of overweight is growing in developed countries, reaching a prevalence of more than $50 \%$ in countries such as the United States. Furthermore, it is alarming that the incidence of overweight in developing countries is also very high [1,2]. Worldwide, diabetes one of the most prevalent co-morbidities associated with obesity, which is also related with several types of cancer, including tumors of the breast, colon, endothelium, and rectum, while there is a lower risk associated with other types of tumors, such as prostate cancer [3-5]. Several studies have suggested that diabetes is a weak prognostic factor in cancer patients $[3,5]$. The role of metabolic dysfunction, such as hyperinsulinemia, in the increased risk for cancer remains to be clarified. For more than 4 decades, a biguanide oral antihyperglycemic, metformin, has been used to treat diabetes patients throughout the world. Metformin treatment improves hyperglycemia in diabetic patients, ameliorating their health condition $[6,7]$. Overall, metformin increases tissue insulin sensitivity, which reduces glycemia, and it also decreases the insulin demand [8]. It has been suggested that decreased insulinemia, indirectly stimulated by metformin, reduces the activity of cellular proliferative pathways via protein kinases, such as AMP-activated kinase (AMPK) [9]. It has also been suggested that, through the AMPK pathway, metformin inhibits the mammalian target of rapamycin (mTOR) gene, which is involved in regulating protein synthesis and cell proliferation $[9,10]$. Epidemiological studies and some short-term clinical trials have indicated that metformin reduces the risk of cancer in diabetic and non-diabetic populations [11-15]. However, experimental works investigating the long-term anticancer effects of metformin treatment are lacking.

The present work investigate whether, prior the Walker 256 tumor cells graft, chronic metformin treatment is able to reduce tumor growth dependent or independent of metabolism improvement.

\section{Materials and Methods}

\section{Animals}

Newborn male Wistar rats were treated once a day with monosodium L-glutamate [MSG, $4 \mathrm{mg} / \mathrm{g}$ body weight (bw); Sigma-Aldrich, Germany] during the first 5 days after birth, MSG was injected subcutaneously into the cervical area of Wistar rat pups. Control animals were injected with an equimolar saline solution. The pups were weaned at 21 days of age [16].

During all experimental protocols, rats were kept at a temperature of $23 \pm 2{ }^{\circ} \mathrm{C}$, a light/dark cycle of $12 \mathrm{~h}$ and given free access to water and a standard rodent chow diet (Nuvital ${ }^{\circledR}$, Curitiba, PR, Brazil). The protocols for the experiments were approved by the Ethics Committee for Animal Experimentation of the State University of Maringá.

\section{Metformin treatment}

Just after weaning, one batch of animals from Control and MSG groups was treated with metformin (Metformin hydrochloride, Medley, Brazil), dissolved in water, at a dose of $250 \mathrm{mg} / \mathrm{kg}$ of bw, by gavage once a day, from 21 to 100 days old (Fig. 1). Another batch of animals from Control and MSG groups received water. The metformin treatment was performed by 80 days. Compared with other studies the metformin dose used in the present work have no detectable toxicity to experimental animal $[17,18]$. After the metformin treatment was finished, some of the animals of both groups Control and MSG were used in the subsequent experimental proceedings, and some were used to inoculate tumor cells.

\section{Assessment of obesity}

At 101-day-old, a batch of animals from each experimental group, Control and MSG, treated or untreated with metformin, after 12-h fasting was weighed, anesthetized (thiopental $45 \mathrm{mg} / \mathrm{kg} \mathrm{bw}$ ), and the length was measured as the nasal anal length (NAL) to calculate the Lee index or body mass index using the following equation: Lee index $=(\mathrm{bw}[\mathrm{g}] 1 / 3 / \mathrm{NAL}[\mathrm{cm}]) \times 1000$, which was used to obesity assessed [19]. After 
the last measurements, the animals were decapitated so that the mesenteric fat pad could be removed and weighed.

\section{Intravenous glucose tolerance test (ivGTT)}

Under ketamine and xylazine anesthesia ( 3 and $0.6 \mathrm{mg} / 100 \mathrm{~g}$ bw, respectively), a silicone cannula was implanted into the right jugular vein of animals from both groups, Control and MSG treated or untreated with metformin and stabilized on the dorsal region of the neck. The cannula was previously treated with heparinized saline [50 IU heparin $/ \mathrm{ml} 0.9 \%$ of saline solution] to avoid blood clots. After 24-h of the surgery and 12-h fast (19:00-07:00 h), without any anesthesia, a glucose load (1 g/kg bw) was infused into the animals' vein through the cannula. Blood samples were collected immediately before the glucose load (zero time) and at $5,15,30$ and $45 \mathrm{~min}$. Plasma obtained from blood samples was stored at $-20^{\circ} \mathrm{C}$ for subsequent determination of the glucose concentration by the glucose oxidase method [20] using a commercial kit (Gold Analisa ${ }^{\circledR}$, Belo Horizonte, MG, Brazil) and for the determination of insulin levels using a radioimmunoassay (RIA) [21].

\section{Insulin sensibility}

Another batch of rats from both Control and MSG groups, treated or untreated with metformin, underwent a surgery to cannula implantation. After a 6-h fast and without any anesthesia the rats were submitted to an intraperitoneal insulin tolerance test (ipITT; $1 \mathrm{U} / \mathrm{kg}$ bw of insulin). Samples for blood glucose measurements were collected at zero (basal), 5, 15, 30 and 45 min after insulin injection, as described for the ivGTT. Thereafter, the glucose tissue uptake rate or the rate constant for plasma glucose disappearance $\left(K_{i t t}\right)$ was calculated using the formula $0.693 /(\mathrm{t} 1 / 2)$, as indicated in a previous report [22]. The plasma glucose $t 1 / 2$ was calculated from the slope of the least square analysis of the plasma glucose concentrations during the linear phase of decline.

\section{Pancreatic islets isolation}

Pancreatic islets were isolated using the collagenase technique as previously described [23] with some adaptations. At 101 days of age, rats from Control and MSG groups treated or untreated with metformin were anesthetized with thiopental ( $45 \mathrm{mg} / \mathrm{kg}$ of bw) and decapitated, and the abdominal wall was cut and open. Then, $8 \mathrm{ml}$ of Hanks buffered saline solution [HBSS, (mmol l-1): $\mathrm{NaCl}, 136.9 ; \mathrm{KCl}, 5.4 ; \mathrm{MgSO}_{4} 7 \mathrm{H}_{2} \mathrm{O}$, $0.81 ; \mathrm{Na}_{2} \mathrm{HPO}_{4}, 0.34 ; \mathrm{KH}_{2} \mathrm{PO}_{4}, 0.44 ; \mathrm{CaCl}_{2} 2 \mathrm{H} 2 \mathrm{O}, 1.26$; $\mathrm{NaHCO}_{3}$, 4.16; glucose, 0.06; BSA (bovine serum albumin) 15 and $\left(\mathrm{O}_{2}, 95 \%+\mathrm{CO}_{2}, 5 \%\right.$ mixed) $\left./ 10 \mathrm{~min}, \mathrm{pH} 7.4\right]$ containing (collagenase type $\mathrm{XI}, 0.1 \%$ plus BSA, 5\% and HEPES [N-(2-hydroxyethyl-piperazine)-N'-(2-ethanesulphonic acid)], 0.6\%, Sigma-Aldrich ${ }^{\circledR}$, St. Louis, MO, USA) was injected into the common bile duct. The pancreas was swollen with the collagenase solution and quickly excised and incubated in a glass beaker for $17-18 \mathrm{~min}$ at $37^{\circ} \mathrm{C}$. The suspension was then discarded and washed with HBSS in 3 continuous washings. The islets were collected with the aid of a stereomicroscope. At least 3 rats from each of 3 different litters were used for each experimental procedure with each animal group.

\section{Insulin secretion stimulation}

To adapt the isolated islets to a baseline glucose concentration $\left(5.6 \mathrm{mmol} \mathrm{l}^{-1}\right)$, the cells were preincubated for $60 \mathrm{~min}$ in $1 \mathrm{ml}$ of normal Krebs-Ringer solution [( $\mathrm{mmol} \mathrm{l}^{-1}$ ): $\mathrm{NaCl}, 115 ; \mathrm{NaHCO}_{3^{\prime}}$ 24; KCl, 1.6; $\left.\mathrm{MgCl}_{6} \mathrm{H}_{2} \mathrm{O}, 1 ; \mathrm{CaCl}_{2} 2 \mathrm{H}_{2} \mathrm{O}, 1 ; \mathrm{BSA}, 15\right]$ at $\mathrm{pH} 7.4$ containing $5.6 \mathrm{mmol} \mathrm{l}^{-1}$ glucose. This solution was gassed with $\left(\mathrm{O}_{2}, 95 \%+\mathrm{CO}_{2}, 5 \%\right.$ mixed) to maintain a $\mathrm{pH}$ of 7.4 . To study insulinotropic effect of glucose, after preincubation, the islets were incubated for an additional $60 \mathrm{~min}$ in Krebs-Ringer solution containing glucose at different concentrations: $5.6 ; 8.3 ; 11.1 ; 16.7 ; 20.0$ and $24.0 \mathrm{mmol}^{-1}$. The insulin secretion was determined by its concentration in samples from the supernatant at the end of incubations; the insulin levels were measured by RIA [21].

\section{Inoculation of Walker 256 cells}

The tumor Walker 256 is a spontaneous carcinosarcoma from rat mammary gland, that present aggressive biological behavior, locally invasive, with high capacity of metastasis via lymphatic and hematogenous systems [24]. The Walker 256 cells were maintained intraperitoneally in rats. After one week the cells were collected, centrifuged, resuspended in phosphate buffered saline (PBS; $16.5 \mathrm{mmol} \mathrm{l}^{-1}$ of phosphate, $137 \mathrm{mmol} \mathrm{l}^{-1}$ of NaCl and $2.7 \mathrm{mmoll}^{-1}$ of KCl), $\mathrm{pH} 7.4$, and the cell viability was evaluated using the 


\section{Experimental Protocol}

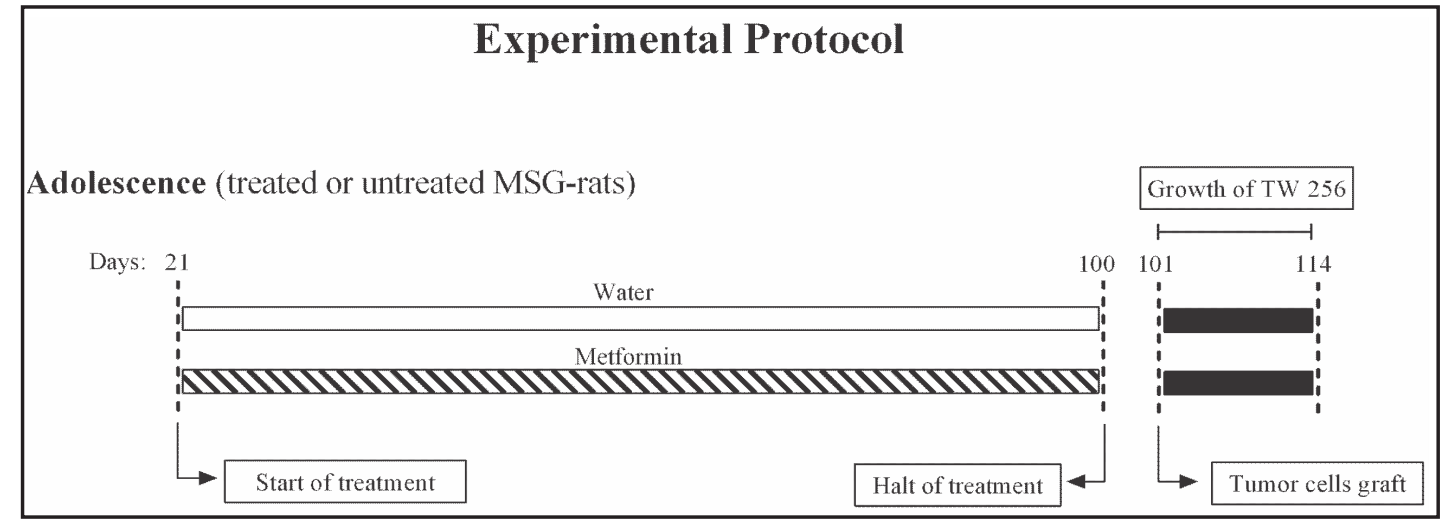

Fig. 1. Schematic diagram of the experimental protocol.

method of trypan blue exclusion. A batch of Control and MSG rats, at 101 days old, treated or untreated with metformin were inoculated subcutaneously with $8.0 \times 10^{7}$ viable tumor cells/animal into their right rear flanks [25]. The inoculation of the Walker 256 tumor cells was performed 24-h after metformin treatment stopped, as shown in Fig. 1.

\section{Tumor evaluation and Characterization of cachexia}

After 14 days of inoculation, 12-h fasting rats were anesthetized (thiopental $45 \mathrm{mg} / \mathrm{kg} \mathrm{bw}$ ) and sacrificed by decapitation and blood samples were collected. Their tumor mass were carefully dissected and weighed to calculate the percentage of body weight loss. The loss of bw was calculated as follows: LBW (\%) $=100 \times($ bwi - bwf + tm + gbw)/(bwi + gbw); where LBW: loss of body weight; bwi: initial body weight (g), and bwf: final body weight $(\mathrm{g})$ of rats with tumor; tm: tumor mass $(\mathrm{g})$; and gbw: body weight gain $(\mathrm{g})$ of rat without tumor during the 14 days the experiment. The rats were considered cachectic when the LBW was higher than $10 \%$ [25].

\section{Hematoxylin-eosin staining (H \& E) and TUNEL assay}

The samples of tumor Walker 256 from each experimental group were collected and fixed in $4 \%$ paraformaldehyde, dehydrated with a graded alcohol series, diaphanized, bathed in xylene and embedded in paraffin. The $6 \mu \mathrm{m}$ thick sections were cut with a rotary microtome, mounted on slides and stained with $\mathrm{H} \& \mathrm{E}$, to confirm apoptosis in morphological criteria. The slides were analyzed with an optical microscope for the overall assessment of tumor tissue.

The presence of apoptotic cells was investigated by TUNEL assay using the ApopTag Plus Peroxidase In situ Apoptosis Detection kit (Chemicon, Cat no: S7101, USA) according to the manufacturer's instructions. Walker 256 tumor tissues were deparaffinized using xylene dehydrate with a series of alcohol rinses and washed with PBS. The sections were incubated with a $20 \mu \mathrm{g} / \mathrm{mL}$ of proteinase $\mathrm{K}$ for 30 min for protein digestion. Then, tissues were incubated with 3\% hydrogen peroxide for 5 min to prevent endogenous peroxidase activity. After washing with PBS, the sections were incubated with Equilibration Buffer. The slides were treated with TdT Enzyme at $37^{\circ} \mathrm{C}$ for $60 \mathrm{~min}$. After that, the sections were incubated in Stop/ wash Buffer for $10 \mathrm{~min}$ and incubated in Anti-Digoxigenin-Peroxidase for $30 \mathrm{~min}$. Apoptotic cells were observed using the Diaminobenzidine (DAB) substrate. Subsequently, the sections were counterstained with Mayer's hematoxylin, and then mounted. Reaction buffer instead of TDT enzyme was used in negative control tissue preparations. Slides were observed and evaluated using an optical microscope.

\section{Apoptosis quantification}

Apoptosis in the Walker 256 tumor tissues was quantified by morphometric analysis as previously described [26] with minor modifications. Summarized, the area of TUNEL-positive cells was measured in five images of randomly selected fields at 400x magnification from 2 or 3 rats, using software for morphometric analysis (Image-Pro Plus software v. 4.5, Media Cybernetics, Silver Spring, MD). The percentage of apoptotic area was calculated from the areas of tumor tissues: \% apoptotic area (Apoptotic index: $\mathrm{AI})=($ apoptotic cells area / non-apoptotic cells area) X 100. 
Fig. 2. Effect of chronic metformin treatment on glycemia and insulinemia during the ivGTT. The symbols represent the mean \pm SEM of the A) plasma glucose levels and B) insulin concentration. The AUC indicates the mean \pm SEM calculated from the glycemia and insulinemia oscillations. The letters over the bars represent statistical significant differences using one-way ANOVA $(P<0.0001)$ among the groups.

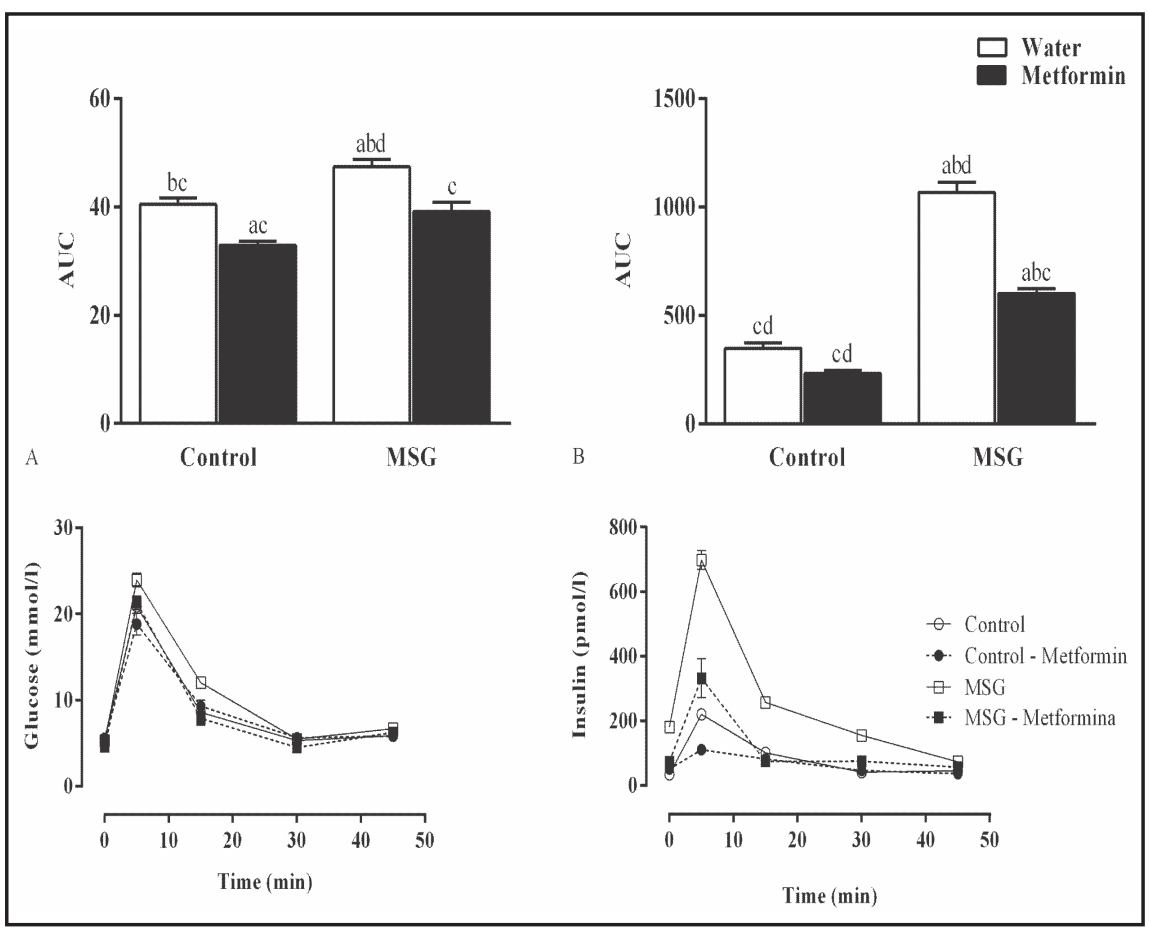

Table 1. Biometric parameters of the Control and MSG animals treated or no with metformin. The data represent the mean \pm SEM obtained from 12 rats of each experimental group. The adult rats came from 4 distinct litters. Values within a row with unlike superscript letters were significantly different based on oneway ANOVA $(P<0.0001)$ among the groups. The letters a, b, c and d represent the groups: Control, Control treated with metformin, MSG and MSG treated with metformin respectively

\begin{tabular}{lcccc}
\hline Biometric Parameters & Control $^{\mathrm{a}}$ & Control Metformin $^{\mathrm{b}}$ & MSG $^{\mathrm{c}}$ & MSG Metformin $^{\mathrm{d}}$ \\
\hline Final Body Weight $(\mathrm{g})$ & $377.0 \pm 6.7^{\mathrm{cd}}$ & $364.5 \pm 5.9^{\mathrm{cd}}$ & $289.2 \pm 7.1^{\mathrm{abd}}$ & $237.0 \pm 9.1^{\mathrm{abc}}$ \\
Body Length $(\mathrm{cm})$ & $22.7 \pm 0.2^{\mathrm{cd}}$ & $22.8 \pm 0.1^{\mathrm{cd}}$ & $19.3 \pm 0.2^{\mathrm{ab}}$ & $19.3 \pm 0.2^{\mathrm{ab}}$ \\
Lee Index & $31.8 \pm 0.2^{\mathrm{c}}$ & $31.0 \pm 0.2^{\mathrm{c}}$ & $33.7 \pm 0.3^{\mathrm{abd}}$ & $31.8 \pm 0.3^{\mathrm{c}}$ \\
\hline
\end{tabular}

Statistical analyses

The results are given as the mean \pm SEM and were submitted to a Student's $t$ test or one-way analyses of variance (one-way ANOVA), followed by a Bonferroni $t$ test. $p<0.05$ was considered statistically significant. The tests were performed using GraphPad Prism version 5.0 for Windows (GraphPad Software Inc., San Diego, CA, USA).

\section{Results}

Characterization of MSG-obesity and metabolism

Table 1 shows that neonatal MSG treatment provoked a 23\% decrease in bw when compared to control rats, $P<0.0001$. Whereas chronic metformin treatment in the control animals did not cause any change, the bw was decreased 19\% in the MSG animals, $P<0.0001$. The body length was reduced by $14 \%$ due to neonatal treatment with MSG, $P<0.0001$. Chronic metformin treatment did not affect the body length in both groups control and MSG. MSG treatment induced a $6 \%$ increase in the Lee index, $P<0.0001$, while chronic metformin treatment caused a $6 \%$ reduction in the MSG rats, $P<0.0001$, without causing any changes in the control rats. 
Fig. 3. The effect of chronic metformin treatment on the rate constant for plasma glucose disappearaence $\left(K_{i t t}\right)$, during ipITT. The symbols represent the mean \pm SEM of the plasma glucose levels during the ipITT. In the insert of Fig., the bars represent the mean \pm SEM of $K_{i t t^{*}}$ The letters over the bars represent statistical significant differences using one-way ANOVA $(P<0.0001)$ among the groups.
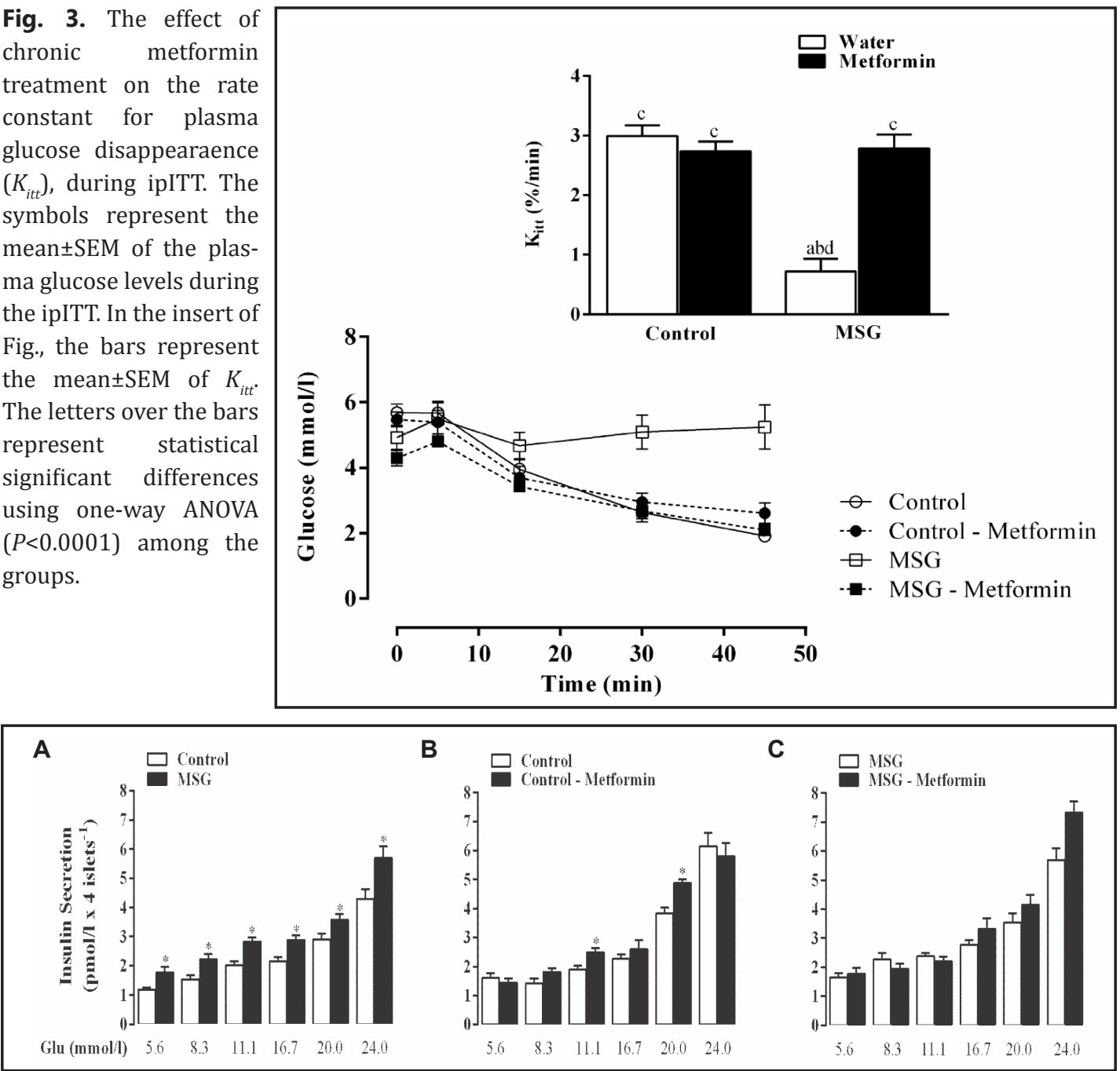

Fig. 4. Glucose-induced insulin release from isolated rat pancreatic islets. The symbols represent the mean \pm SEM of insulin secretion stimulated by glucose in pancreatic islets isolated from at least 8 rats of each experimental group. A) Control versus MSG, B) control versus control treated with metformin and C) MSG versus MSG treated with metformin. The Student's t-test was used to compare each glucose concentration, ${ }^{*} P<0.05$ indicated a significant difference between groups for each Figure.

The neonatal treatment with MSG provoked a 20\% increase in the area under curve (AUC) of glycemia during ivGTT compared to Control rats, $P<0.0001$, as shown in the insert of Fig. 2A. While chronic metformin treatment reduced glycemia of Control rats by $14 \%$, in the MSG rats it was decreased by $17 \%(P<0.0001$; Fig. $2 A)$.

As shown in the insert of Fig. 2B, the ivGTT also revealed that MSG treatment caused a hyperinsulinemia of $68 \%$ in the AUC of insulinemia when compared to the Control rats, $P<0.0001$. However chronic metformin treatments decrease $44 \%$ and $34 \%$ of the total insulinemia of MSG and Control animals, respectively, $\mathrm{P}<0.0001$.

Fig. 3 shows data from ipITT. Neonatal treatment with MSG caused a 4-fold decrease in $K_{i t t^{\prime}} P<0.0001$. While chronic metformin treatment did not change $K_{i t t}$ in control rats, the MSG rats metformin treated presented a 4 -fold increase, $P<0.0001$.

Different glucose concentrations induced insulin secretion in a concentrationdependent manner in rat pancreatic islets from both Control and MSG experimental groups, treated or untreated with metformin, in Fig. 4A, 4B and 4C. Whereas islets from MSG rats displayed greater insulin secretion than islets from Control rats, as shown in Fig. 4A, shifting 


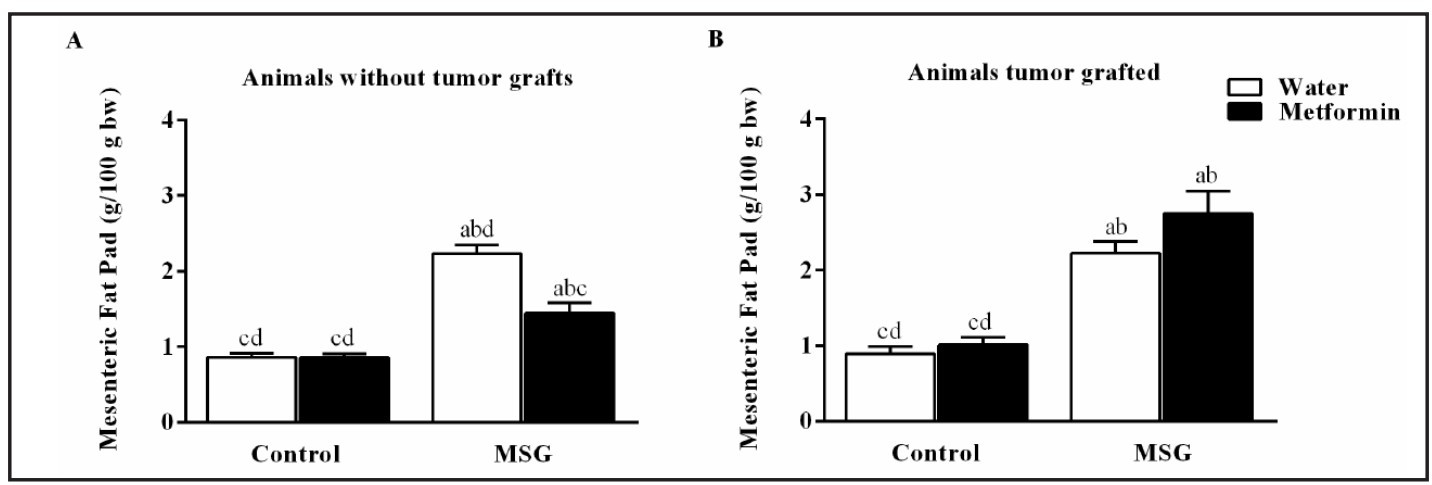

Fig. 5. The effect of chronic metformin treatment on fat pad stores of rats. The bars represent the mean \pm SEM of mesenteric fat pad: A) Animals without tumor and B) Animals with tumor. The letters over the bars represent statistical significant differences based on one-way ANOVA $(P<0.0001)$ among the groups.

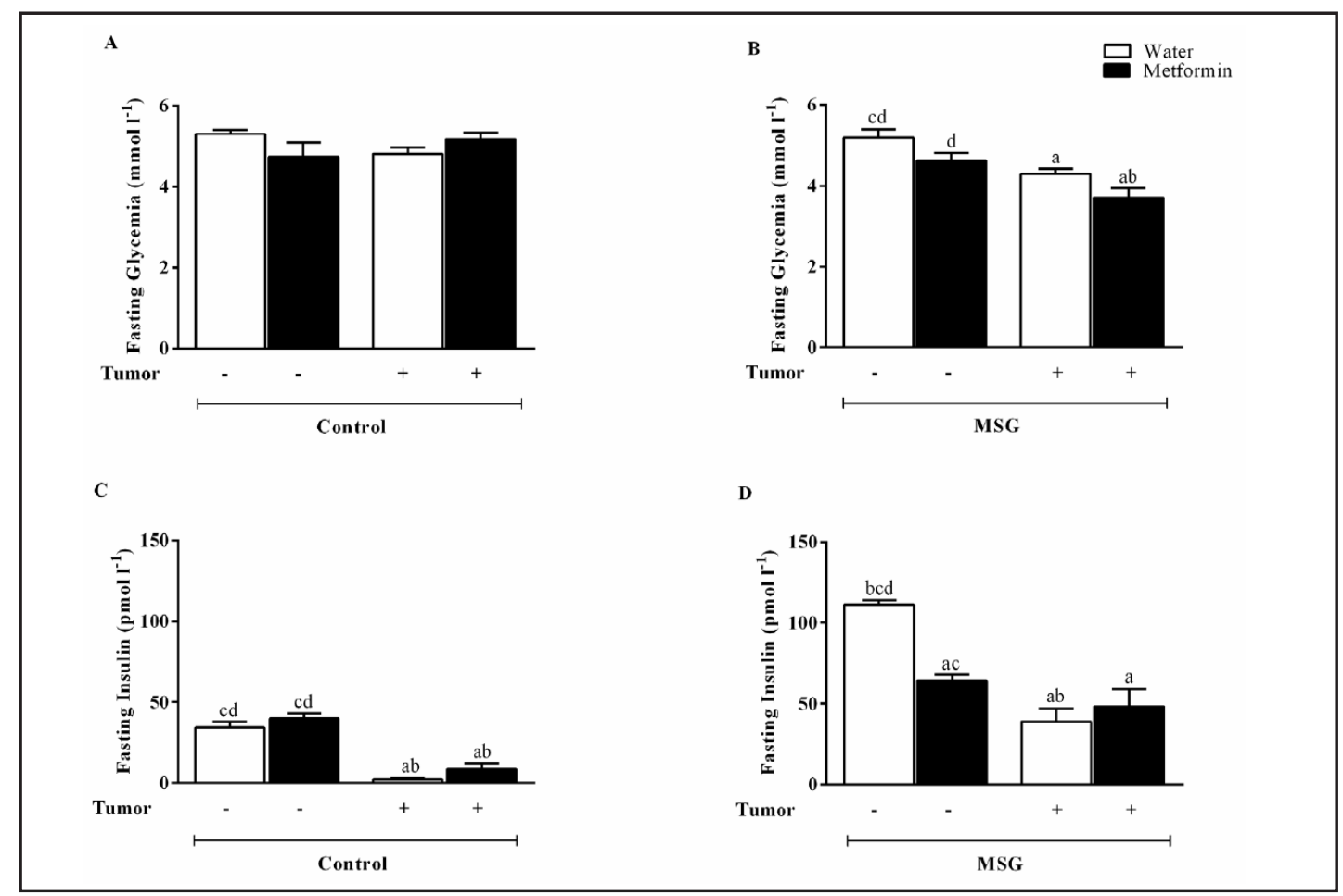

Fig. 6. Effect of chronic metformin treatment on fasting glycemia and insulinemia in rats inoculated with Walker 256 tumor cells. The bars represent the mean \pm SEM of the fasting plasma glucose concentration in A) Control rats and B) MSG rats and fasting plasma insulin levels from C) control rats and D) MSG rats. The letters over the bars represent statistical significant differences using one-way ANOVA $(P<0.0001)$ among the groups. The symbols (-) and (+) indicate the absence and presence of the tumor, respectively.

the curve to left, $P<0.05$, chronic metformin treatment did not change the glucose-induced insulin secretion curve of Control and MSG animals.

The neonatal MSG treatment induced a 2-fold increase in fat tissue accumulation compared with control rats, $P<0.0001$, as show in Fig. 5A; however, chronic administration of metformin reduced fat accretion by $35.4 \%$ in MSG rats $(P<0.0001)$, while it did not change the fat pad mass in control rats.

Walker 256 tumor growth and metformin protect effects

Tumor growth did not alter fat tissue accumulation in both Control and MSG groups, $P<0.0001$, as shown in Fig. 5B. Fig. 6 presented the fasting glycemia and insulinemia for all experimental groups. There was no difference in glycemia among the control group treated 


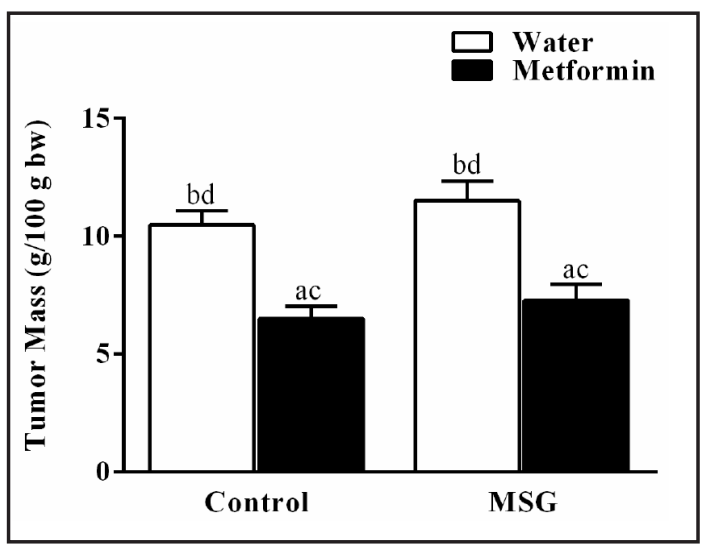

Fig. 7. Tumor growth. Bars represent the mean \pm SEM of the tumor mass related to bw. The letters over the bars represent statistical significant differences by one-way ANOVA $(P<0.0001)$ among the groups.

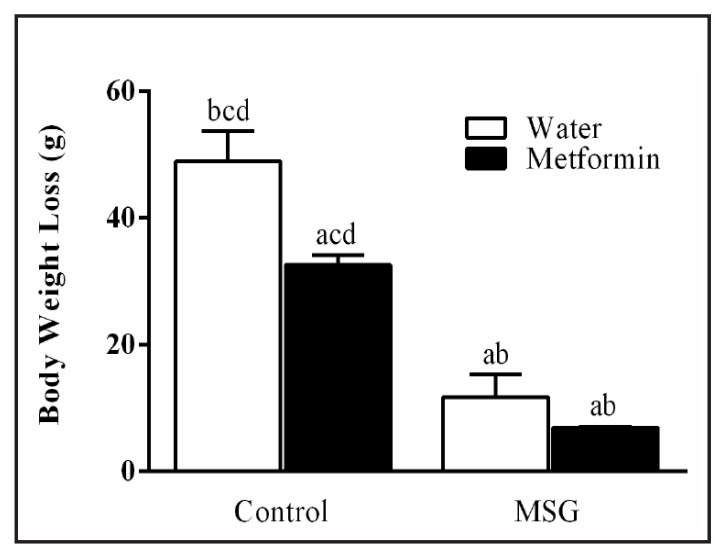

Fig. 8. Body Weight Loss. The bars represent the mean \pm SEM of bw loss from rats grafted with Walker 256 cells. The zero line represents the $100 \%$ of the bw from rats that has been not grafted with Walker 256 cells, to each treatment. The letters over the bars represent statistical significant differences using one-way ANOVA $(P<0.0001)$ among the groups.

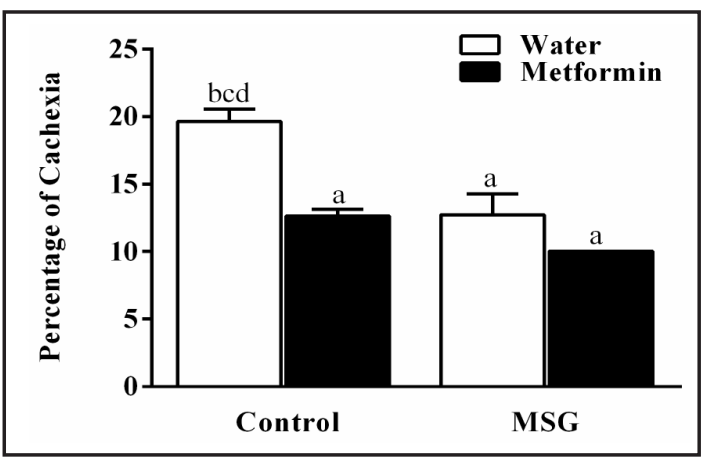

Fig. 9. Percentage of Cachexia. The bars represent the mean \pm SEM of $\%$ of rats that loss more than 10 $\%$ of bw. The letters over the bars represent statistical significant differences using one-way ANOVA $(P<0.0001)$ among the groups.

or untreated with metformin and inoculated or not with the Walker 256 tumor (Fig. 6A). The tumor-bearing MSG rats showed a 20\% decrease in the plasma glucose concentration compared to the MSG rats that were not grafted with tumor cells, $P<0.0005$, as shown in Fig. $6 \mathrm{~B}$. The fasting glycemia was reduced in both tumor grafted MSG animals, regardless of the metformin treatment.

Fasting insulinemia was increased 3-fold in the MSG animals compared with the control animals, $P<0.0001$, as shown in Fig. 6C and 6D. While chronic metformin treatment did not change fasting insulinemia in the control animals, there was a $61 \%$ decrease in the MSG rats. Tumor transplantation decreased the fasting plasma insulin levels in both control and MSG groups; however, there was a 10-fold reduction in the control rats and a 3-fold in the MSG rats. Tumor-grafted control animals treated with metformin showed a decrease of 5 -fold in the fasting insulinemia $(P<0.0001)$; while it was not changed in the MSG rats treated with metformin (Fig. 6C and D).

As shown in Fig. 7, the tumor growth was attenuated by $37 \%$ in rats, with a prior chronically treatment with metformin, to both groups, $P<0.0001$.

Tumor growth caused a higher bw loss in Control rats $(48.8 \pm 4.8 \mathrm{~g})$ than in MSG rats $(11.7 \pm 3.5 \mathrm{~g}), P<0.0001$; whereas, chronic metformin treatment reduced the bw loss significantly in control group $(P<0.0001)$, it was not observed in the MSG rats, as shown in Fig. 8.

The cachexia was $19.6 \%$ and $12.7 \%$ in rats from control and MSG groups, respectively; while chronic metformin treatment decreased it by $12.6 \%$ and $10.0 \%$ in both control and MSG groups, $P<0.0001$; as presented in Fig. 9. 
Fig. 10. Microscopic analysis of Walker 256 tumor cells by hematoxylin and eosin staining X40. Data were obtained from Walker 256 tumor tissues from 5-6 rats, at least 3 different litters to both experimental groups. A) Control rats, B) control rats treated with metformin, C) MSG rats and D) MSG rats treated with metformin. The black arrowheads indicate apoptotic cells and white arrowhead indicate necrosis cells.

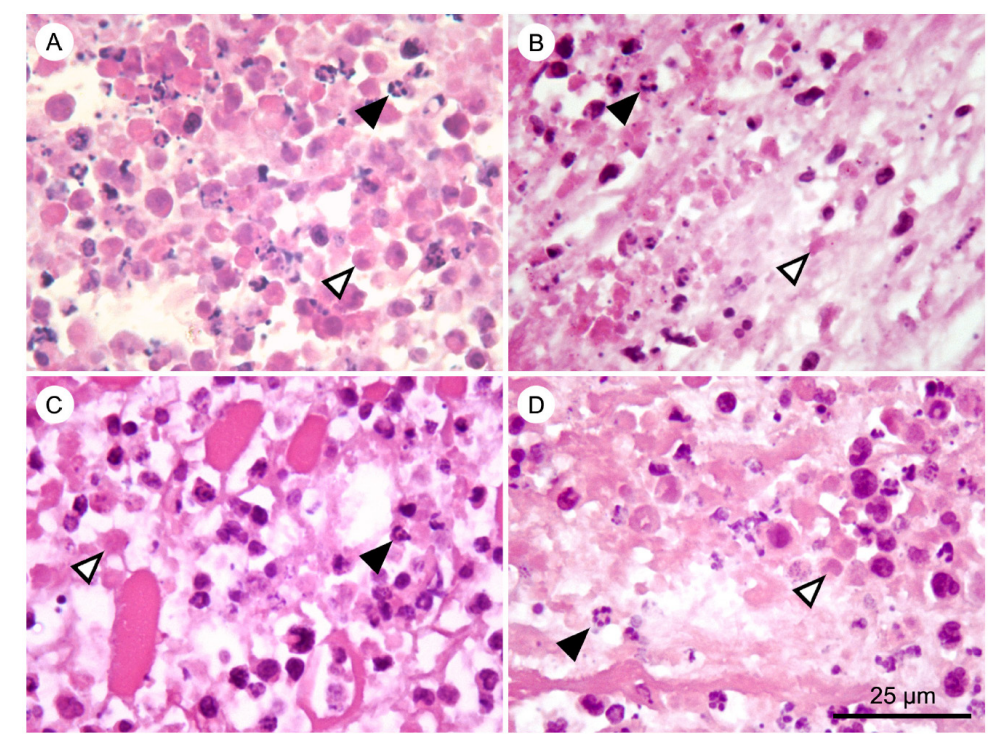

Fig. 11. TUNEL assay for the Walker 256 tumor sections. The slides show positive staining reaction in the staining brown nuclei. A) Control rats, B) control rats treated with metformin, C) MSG rats and D) MSG rats treated with metformin. The pictures were captured in an original magnification $\mathrm{X} 40$.

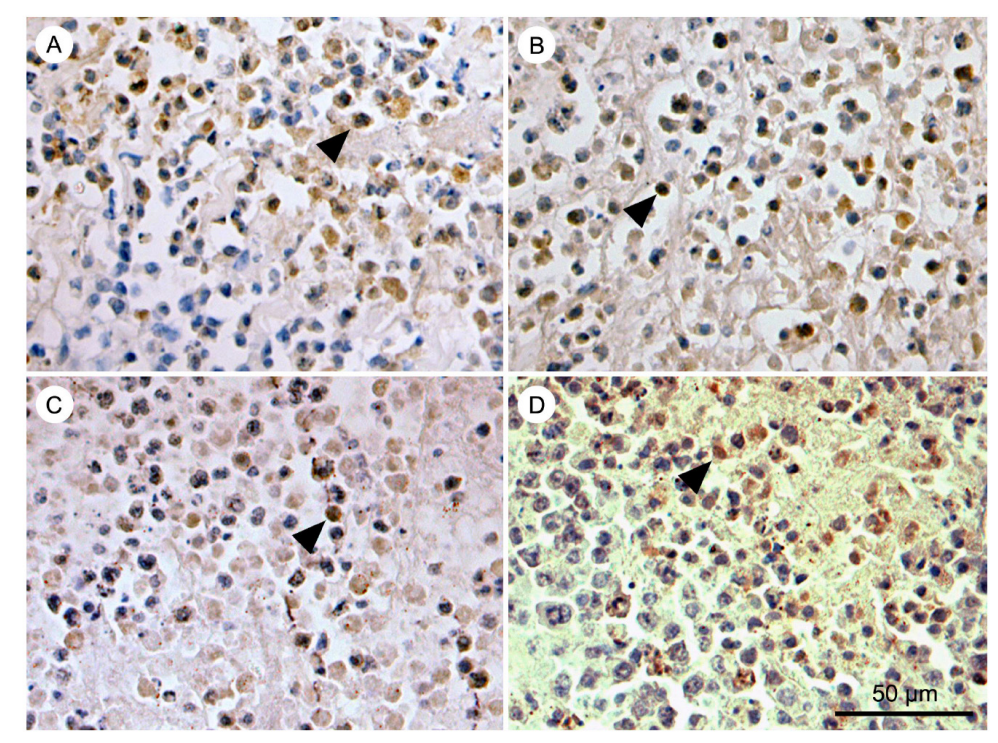

Microscopically histological staining with H \& E shows, that Walker tumor cells displayed similar features in all groups (Fig. 10A and 10D). However, the area of zonal necrosis was more prominent in rats treated with metformin, as show in Fig. 10B and 10D.

The TUNEL assay visually evaluated using sections from tumor Walker 256. Tumor cells revealed strong, brown, positive staining in their nuclei and some of them showed fragmented nuclei in both control and MSG group (Fig. 11A and 11C). The positive staining reaction was remarkably increased in tumor cells from rats treated with metformin (Fig. 11B and $11 \mathrm{D}$ ). AI was similar to lean and obese-MSG rats pre-treated with metformin, increasing $38.9 \%$ and $41.8 \%$ respectively (Fig. 12 ).

\section{Discussion}

As expected, in the present study we confirm previous reports regarding impaired metabolic hallmarks that are well recognized in the MSG model of pre-diabetic obese rats that display massive adipose tissue accumulation, peripheral insulin resistance associated to high glucose-induced insulin secretion [16]. In addition, metformin treatment improved the 
Fig. 12. Apoptotic index. The percentage of apoptotic area was calculated from tumor tissue areas. TUNEL-positive cells were measured in five randomly selected fields images at 400x magnification from 2 or 3 rats. The letters over the bars represent statistical significant differences using one-way ANOVA $(P<0.0001)$ among the groups.

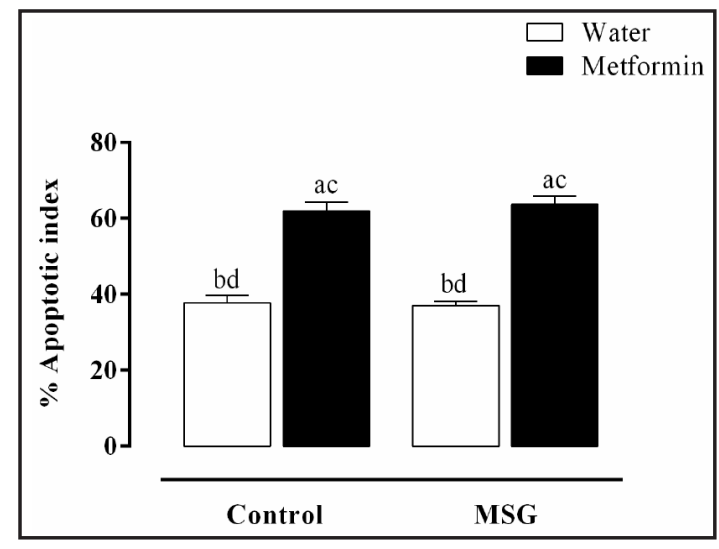

metabolism of MSG prediabetic rats: normalizing the tissue insulin sensitivity and glucose tolerance, reducing fat tissue accretion and suppressing the fasting hyperinsulinemia, as previously reported [27]. By the other hand, metformin treatment did not alter the metabolism of control animals, MSG-untreated rats: insulin sensitivity, glucose tolerance, fasting insulin and glucose levels and fat tissue storage.

Independently of metformin metabolic effect, tumor growth was reduced in both leanand MSG-rats. In human, rodents and isolated cell cultures metformin treatment inhibited tumor growth $[9,28]$. For the first time the present results show that metformin chronic treatment is able to protect both control and MSG animals against tumor growth, even though when the metformin treatment was halted before tumor cells grafts. In contrast, these results are different of short-term metformin treatment effects, which decrease Walker 256 tumor growth, only in obese MSG rats, even though that metformin treatment was initiated with tumor cells graft [29]. Our data suggest that the anticancer effect of metformin is not related to its effects that improve metabolism imbalances, such as hyperinsulinemia, glucose intolerance and fat accretion.

In the current study, during the 14 days of tumor growth, the rats did not receive any metformin doses. Tumor cells were grafted $24 \mathrm{~h}$ after the last dose of metformin treatment, which imply that no traces of the antihyperglycemic agent could be found in the blood stream of the rats. It has been reported that metformin plasma elimination half-life, after oral multiple dosages administration, is around 4-9 h [30,31]; which indicates that metformin might modulate the organism to attenuate tumor growth.

It has been demonstrated that Walker 256 tumor-bearing rats show low levels of plasma insulin, and it decreases glucose-induced insulin secretion in pancreatic beta-cells [32, 33]. Indeed, Walker 256 tumor growth reduced insulin levels 10 -fold in control rats, while in MSG animals the decrease in the insulin levels was only 3-fold. Based on this we can suggest that the Walker 256 tumor interferes with insulin levels as much as a low plasma insulin concentration in metformin-untreated animals, which is in agreement with some previously findings [32, 33].

Rats grafted with Walker 256 tumor cells showed reduced cancer growth when they were treated with exogenous insulin [32, 34]. Unfortunately, the capacity of exogenous insulin to reduce Walker 256 tumor cells growth in MSG-rats was not tested in the current work; although, it has been shown that MSG-rats show severe insulin resistance and high plasma insulin levels [35].

Moreover, metformin did not reduce the glucose insulinotropic effect in isolated pancreatic islets from control and MSG rats. It has been documented that a major effect of metformin on the metabolic improvement is the increase of peripheral tissue insulin sensitivity; however, while reducing insulin resistance in white adipose, muscle and liver tissues, metformin treatment also reduces insulin demand, which may provoke a reduction of blood insulin levels [9].

Tumor growth was the same magnitude in MSG and control rats, the insulin decrease provoked by metformin chronic treatment did not change the cancer aggressiveness. These 
results support the theory that metformin exert a direct inhibitory effect on tumor growth $[36,37]$. At the same line of idea, our data show that Walker 256 tumor cells either in control or MSG-rats treated with metformin presented increased Tunel positive tumor cells, confirming that the antihyperglycemic drug might exert a direct effect on the Walker 256 tumor cells growth.

Although during 14 days there was no treatment with metformin, the drug-treated animals exhibited inhibition of the tumor growth. It allows us to speculate that metformin could protect the rat organism against tumor growth. According to Pearce and colleagues, animals immunized with a vaccine created with the objective of increasing the development of CD8 T lymphocytes, which are responsible by humoral immunological defense, treated with metformin for 3 weeks, showed less mortality after tumor cells inoculation when compared to animals that did not received metformin treatment; even though the drug treatment was halted 24 hours before the tumor grafts, suggesting that treatment with metformin improves the generation of memory $\mathrm{T}$ cells, resulting in enhanced antitumoral protective immunity [38].

It is also possible that metformin reduces the neoangiogenesis, which decreases the capacity of tumor to receive nutrients to the growth. One hallmark of neoangiogenesis is the increased vascular endothelial growth factor (VEGF) levels. In an ovarian tumor treated with metformin, the neoangiogenesis was inhibited showing low levels of VEGF $[39,40]$.

Keeping in mind that the data presented in the current work were obtained using rats and that only one type of tumor was tested, our results are consistent to conclude that early chronic metformin treatment, prior to the tumor cell grafts and/or their growth, induced an imprint effect that attenuated the cancer growth independent of the positive effects of the metformin on metabolism, which indicates a direct effect of metformin on the Walker 256 tumor growth. With respect to the rapid increase of the incidence of cancer around the world, it is important to consider the possible use of metformin to attenuate the suffering and mortality caused by cancer; perhaps it could be used as prophylactic anticancer substance in patients with a predisposition to develop tumors.

\section{Acknowledgments}

We thank to Mr. Luis Augusto Bataglini for his help with the animal protocols. This work was supported by the Brazilian Federal Foundation, the Conselho National de Desenvolvimento Científico e Tecnológico (CNPq), the Coordenação de Aperfeiçoamento de Pessoal de Nível Superior (CAPES), and the Paraná Science Foundation (Fundação Araucária).

\section{Disclosure Statement}

The authors declare that there is no conflict of interest associated with this manuscript.

\section{References}

1 de Campos KE, Sinzato YK, Pimenta Wde P, Rudge MV, Damasceno DC: Effect of maternal obesity on diabetes development in adult rat offspring. Life Sci 2007;81:1473-1478.

2 Megna JL, Schwartz TL, Siddiqui UA, Herrera Rojas M: Obesity in adults with serious and persistent mental illness: A review of postulated mechanisms and current interventions. Ann Clin Psychiatry 2011;23:131140.

-3 Giovannucci E, Harlan DM, Archer MC, Bergenstal RM, Gapstur SM, Habel LA, Pollak M, Regensteiner JG, Yee D: Diabetes and cancer: A consensus report. Diabetes Care 2010;33:1674-1685. 


\section{Cellular Physiology $\quad$ Cell Physiol Biochem 2014;34:1920-1932 and Biochemistry

4 Kasper JS, Giovannucci E: A meta-analysis of diabetes mellitus and the risk of prostate cancer. Cancer Epidemiol Biomarkers Prev 2006;15:2056-2062.

5 Vigneri P, Frasca F, Sciacca L, Pandini G, Vigneri R: Diabetes and cancer. Endocr Relat Cancer 2009;16:11031123.

6 6 Hother-Nielsen O, Schmitz O, Andersen PH, Beck-Nielsen H, Pedersen O: Metformin improves peripheral but not hepatic insulin action in obese patients with type ii diabetes. Acta Endocrinol (Copenh) 1989;120:257-265.

7 Wollen N, Bailey CJ: Inhibition of hepatic gluconeogenesis by metformin. Synergism with insulin. Biochem Pharmacol 1988;37:4353-4358.

$>8$ Strack T: Metformin: A review. Drugs Today (Barc) 2008;44:303-314.

-9 Bost F, Sahra IB, Le Marchand-Brustel Y, Tanti JF: Metformin and cancer therapy. Curr Opin Oncol 2012;24:103-108.

10 Tzatsos A, Kandror KV: Nutrients suppress phosphatidylinositol 3-kinase/akt signaling via raptordependent mtor-mediated insulin receptor substrate 1 phosphorylation. Mol Cell Biol 2006;26:63-76.

11 Evans JM, Donnelly LA, Emslie-Smith AM, Alessi DR, Morris AD: Metformin and reduced risk of cancer in diabetic patients. BMJ 2005;330:1304-1305.

12 Hawley SA, Boudeau J, Reid JL, Mustard KJ, Udd L, Makela TP, Alessi DR, Hardie DG: Complexes between the lkb1 tumor suppressor, strad alpha/beta and mo25 alpha/beta are upstream kinases in the amp-activated protein kinase cascade. J Biol 2003;2:28.

13 Li D, Yeung SC, Hassan MM, Konopleva M, Abbruzzese JL: Antidiabetic therapies affect risk of pancreatic cancer. Gastroenterology 2009;137:482-488.

14 Alimova IN, Liu B, Fan Z, Edgerton SM, Dillon T, Lind SE, Thor AD: Metformin inhibits breast cancer cell growth, colony formation and induces cell cycle arrest in vitro. Cell Cycle 2009;8:909-915.

-15 Sikka A, Kaur M, Agarwal C, Deep G, Agarwal R: Metformin suppresses growth of human head and neck squamous cell carcinoma via global inhibition of protein translation. Cell Cycle 2012;11:1374-1382.

-16 Andreazzi AE, Grassiolli S, Marangon PB, Martins AG, de Oliveira JC, Torrezan R, Gravena C, Garcia RM, Mathias PC: Impaired sympathoadrenal axis function contributes to enhanced insulin secretion in prediabetic obese rats. Exp Diabetes Res 2011;2011:947917.

17 Quaile MP, Melich DH, Jordan HL, Nold JB, Chism JP, Polli JW, Smith GA, Rhodes MC: Toxicity and toxicokinetics of metformin in rats. Toxicol Appl Pharmacol 2010;243:340-347.

18 Yuan H, Li L, Zheng W, Wan J, Ge P, Li H, Zhang L: Antidiabetic drug metformin alleviates endotoxin-induced fulminant liver injury in mice. Int Immunopharmacol 2012;12:682-688.

19 Bernardis LL, Patterson BD: Correlation between ,lee index‘ and carcass fat content in weanling and adult female rats with hypothalamic lesions. J Endocrinol 1968;40:527-528.

20 DuBois RN: Cyclooxygenase-2 and colorectal cancer. Prog ExpTumor Res 2003;37:124-137.

21 Scott AM, Atwater I, Rojas E: A method for the simultaneous measurement of insulin release and b cell membrane potential in single mouse islets of langerhans. Diabetologia 1981;21:470-475.

22 Lundbaek K: Intravenous glucose tolerance as a tool in definition and diagnosis of diabetes mellitus. Br Med J 1962;1:1507-1513.

23 Gravena C, Mathias PC, Ashcroft SJ: Acute effects of fatty acids on insulin secretion from rat and human islets of langerhans. J Endocrinol 2002;173:73-80.

24 Black JM, Nesheim MC, Kinsella JE: Dietary level of maize oil affects growth and lipid composition of walker 256 carcinosarcoma. The British journal of nutrition 1994;71:283-294.

25 Cassolla P, Moreira CC, Liboni TF, Zaia CT, Borba-Murad GR, Bazotte RB, de Souza HM: Changes in blood metabolic parameters during the development of walker-256 tumour-induced cachexia in rats are not caused by decreased food intake. Cell Biochem Funct 2012;30:265-270.

26 Aita K, Irie H, Tanuma Y, Toida S, Okuma Y, Mori S, Shiga J: Apoptosis in murine lymphoid organs following intraperitoneal administration of dimethyl sulfoxide (dmso). Exp Mol Pathol 2005;79:265-271.

27 Lobato NS, Filgueira FP, Hagihara GN, Akamine EH, Pariz JR, Tostes RC, Carvalho MH, Fortes ZB: Improvement of metabolic parameters and vascular function by metformin in obese non-diabetic rats. Life Sci 2012;90:228-235.

28 Viollet B, Guigas B, Sanz Garcia N, Leclerc J, Foretz M, Andreelli F: Cellular and molecular mechanisms of metformin: An overview. Clinical Sci 2012;122:253-270. 
29 Fonseca EAI, de Oliveira MA, Lobato ND, Akamine EH, Colquhoun A, de Carvalho MHC, Zyngier SB, Fortes ZB: Metformin reduces the stimulatory effect of obesity on in vivo walker-256 tumor development and increases the area of tumor necrosis. Life Sci 2011;88:846-852.

-30 Graham GG, Punt J, Arora M, Day RO, Doogue MP, Duong JK, Furlong TJ, Greenfield JR, Greenup LC, Kirkpatrick CM, Ray JE, Timmins P, Williams KM: Clinical pharmacokinetics of metformin. Clin Pharmacokinet 2011;50:81-98.

-31 Scheen AJ: Clinical pharmacokinetics of metformin. Clinical pharmacokinetics 1996;30:359-371.

-32 Fernandes LC, Machado UF, Nogueira CR, Carpinelli AR, Curi R: Insulin secretion in walker 256 tumor cachexia. Am J Physiol1990;258:E1033-1036.

33 el Razi Neto S, Zorn TM, Curi R, Carpinelli AR: Impairment of insulin secretion in pancreatic islets isolated from walker 256 tumor-bearing rats. Am J Physiol 1996;271:C804-809.

34 Moley JF, Morrison SD, Gorschboth CM, Norton JA: Body composition changes in rats with experimental cancer cachexia: Improvement with exogenous insulin. Cancer Res 1988;48:2784-2787.

- 35 Balbo SL, Grassiolli S, Ribeiro RA, Bonfleur ML, Gravena C, Brito Mdo N, Andreazzi AE, Mathias PC, Torrezan R: Fat storage is partially dependent on vagal activity and insulin secretion of hypothalamic obese rat. Endocrine 2007;31:142-148.

-36 Dowling RJ, Niraula S, Stambolic V, Goodwin PJ: Metformin in cancer: Translational challenges. J Mol Endocrinol 2012;48:R31-43.

37 Goodwin PJ: Insulin in the adjuvant breast cancer setting: A novel therapeutic target for lifestyle and pharmacologic interventions? J Clin Oncol 2008;26:833-834.

-38 Pearce EL, Walsh MC, Cejas PJ, Harms GM, Shen H, Wang LS, Jones RG, Choi Y: Enhancing cd8 t-cell memory by modulating fatty acid metabolism. Nature 2009;460:103-107.

-39 Elia EM, Quintana R, Carrere C, Bazzano MV, Rey-Valzacchi G, Paz DA, Pustovrh MC: Metformin decreases the incidence of ovarian hyperstimulation syndrome: An experimental study. J Ovar Res 2013;6:62.

-40 Rattan R, Graham RP, Maguire JL, Giri S, Shridhar V: Metformin suppresses ovarian cancer growth and metastasis with enhancement of cisplatin cytotoxicity in vivo. Neoplasia 2011;13:483-491. 